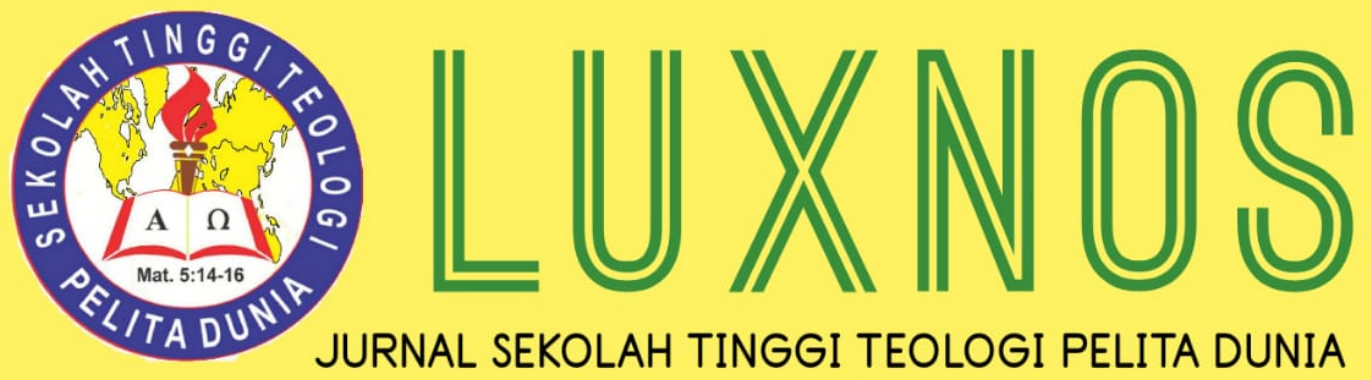

Volume 7 Nomor 2, Desember 2021

P-ISSN : 2527-7561

E-ISSN : 2722-3809

\title{
Studi Evaluasi Terhadap Program Renewal Life di Jemaat GBI El-Shaddai, Pontianak
}

\author{
Naomi Yemima Manalu' ${ }^{1}$, \\ Sekolah Tinggi Teologi Bethel Indonesia \\ naomyemima86@gmail.com \\ Johni Hardori² \\ Sekolah Tinggi Teologi Bethel Indonesia \\ johnihardori@sttbi.ac.id

\section{Robert Paul Trisna ${ }^{3}$ \\ Sekolah Tinggi Teologi Bethel Indonesia robertpaul@sttbi.ac.id}

\begin{abstract}
After believing in Jesus, Christians are required to live in spiritual maturity. This identity encourages each person to experience life changes in all fields. To achieve that goal, God gave the church a task to be able to creatively make programs that can achieve the goals of the congregation's maturity. Starting from cell groups, family altars, to Renewal Life. This study aims to describe the concept of fostering the spiritual faith of the GBI El Shaddai Pontianak congregation through the Renewal Life program, so that the congregation experiences an encounter with the Lord Jesus Christ personally and experiences spiritual maturity. The impact and all the shortcomings of the Renewal Life program of the GBI El Shaddai congregation are important to study in order to gain spiritual growth and maturity of the congregation. This study uses a descriptive qualitative method is part of the subject under study. The results of the study show that the congregation after participating in the Renewal Life program has a different mindset, perspective both towards themselves and towards others, so that they are easy to grow in spiritual maturity. Furthermore, the congregation has its own awareness to want to be involved, take part in church services without being pushed, forced by spiritual leaders to serve.

Keywords: Renewal Life Program, Spiritual Maturity, Community, Discipleship
\end{abstract}

Abstrak: Setelah percaya kepada Yesus, orang Kristen dituntut untuk hidup dalam kedewasaan rohani. Identitas ini mendorong setiap pribadi mengalami perubahan hidup dalam segala bidang. Untuk mencapai tujuan itu, Tuhan memberikan tugas kepada gereja agar dapat secara kreatif membuat program-program yang dapat mencapai tujuan kedewasaan jemaat. Mulai dari kelompok sel, mezbah keluarga, sampai Renewal Life. Penelitian ini bertujuan untuk mendeskripsikan konsep pembinaan iman rohani jemaat GBI El Shaddai Pontianak lewat program Renewal Life, 
sehingga jemaat mengalami perjumpaan dengan Tuhan Yesus Kristus secara pribadi dan mengalami kedewasaan rohani. Dampak dan segala kekurangan dari program Renewal Life jemaat GBI El Shaddai penting untuk dikaji untuk mendapatkan pertumbuhan dan kedewasaan rohani jemaat. Penelitian ini menggunakan metode kualitatif deskriptif adalah bagian dari subjek yang diteliti. Hasil penelitian menunjukkan bahwa jemaat yang setelah mengikuti program Renewal Life memiliki pola pikir, cara pandang yang berbeda baik terhadap dirinya sendiri maupun terhadap orang lain, sehingga mudah mengalami pertumbuhan dalam kedewasaan rohani. Selanjutnya, jemaat memiliki kesadaran tersendiri untuk mau terlibat, ambil bagian dalam pelayanan di gereja tanpa harus didorong, dipaksa oleh pemimpin rohani untuk melayani.

Kata Kunci: Program Renewal Life, Kedewasaan Rohani, Komunitas, Pemuridan

\section{Pendahuluan}

Ditemukan adanya indikasi bahwa GBI El Shaddai Pontianak, pelayanannya kurang maksimal karena masih banyak jemaatnya yang belum mengalami pembaruan hidup sejak tahun 2014 sampai 2020. Melihat peristiwa ini maka diperlukan adanya program Renewal Life yang menjadi jawaban. Indikasi ini berangkat dari pertumbuhan kualitas dan kuantitas jemaat yang cenderung statis dan masih tetap hidup dalam kebiasaan lama. Yang dimaksudkan kebiasaan lama adalah kehidupan jemaat sebelum mengenal Kristus. Renewal Life adalah program pelayanan pemulihan jemaat di GBI El Shaddai Pontianak. Melalui pelayanan ini setiap jemaat yang mengalami keterikatan akan dosa masa lalu, luka batin, kutuk okultisme, kutuk keturunan dan dosa lainnya dapat dilayani lewat program ini. Akibat adanya dosa masa lalu yang belum dibereskan atau kutuk nenek moyang yang belum diputuskan membuat jemaat belum sungguhsungguh menghidupi firman Tuhan. Bahkan jemaat hanya menjadi jemaat yang biasabiasa saja tidak ada kerinduan atau kemauan untuk menjadi saksi, tidak mau memberi diri bergabung dalam pelayanan gereja. Padahal seperti yang dikemukakan oleh Adi Putra bahwa pertumbuhan gereja harus dimulai dari pertumbuhan kualitas barulah kepada kuantitas. Ketika anggota jemaat belajar dengan tekun Firman Tuhan sehingga mengerti dan memahaminya, maka mereka akan keluar untuk memberitakan Injil dan bersaksi, sehingga kemudian memberikan pertumbuhan jemaat atau gereja. ${ }^{1}$

Program Renewal Life membawa motto atau wacana yang bersifat merangsang bagi pesertanya. Ketika mengikuti program ini, peserta telah memiliki harapan pribadi akan perubahan hidupnya. Tentunya karena sistem yang dibangun agar tidak menjadi layanan atau program yang takut diikuti oleh jemaat. Hasil di lapangan, setelah peserta dari GBI El Shaddai mengikutinya, terdapat perubahan-perubahan yang amat penting dalam konteks masyarakat Kalimantan Barat. Dimulai dari mengetahui gambar diri dan

1 Adi Putra, "Hakikat Pertumbuhan Gereja Berdasarkan Kisah Para Rasul 2: 41-47," BIA': Jurnal Teologi dan Pendidikan Kristen Kontekstual 3 (2020): 262-281. 
tujuan mereka diciptakan di dunia ini. Program pelayanan ini bertujuan untuk memperlengkapi seluruh jemaat Kristus untuk maju bergerak sesuai dengan kepenuhan Kristus dan memenuhi panggilan mereka, sehingga apabila mereka sudah mengalami pembaharuan hidup mereka akan lebih maksimal dalam melakukan tugas pelayanan. ${ }^{2}$ Mereka juga akan dapat melayani orang lain dan membimbing jiwa-jiwa yang belum diselamatkan kepada Kristus dan Tuhan dipermuliakan lewat pelayanan ini. Menjadi hal yang penting bagi GBI El Shaddai karena jemaat yang berasal dari Kalimantan Barat, daerah yang terkenal mistisnya seperti Kalimantan Tengah. ${ }^{3}$ Bukan hanya itu, konteks Kalimantan Barat juga terdapat insan-insan yang tidak memiliki keutuhan gambar diri, kebencian, luka batin dan lain sebagainya akibat kelahiran yang tidak diinginkan oleh orang tuanya. ${ }^{4}$

Seseorang tidak begitu memahami mengapa karakter atau keadaan hidup yang berhubungan dengan sifat-sifat seseorang menjadi begitu rumit yang akhirnya banyak menimbulkan masalah. ${ }^{5}$ Ternyata ada namanya akar-akar permasalahan dalam kehidupan seseorang yang harus dibereskan. Jika akar tersebut tidak dicabut, maka akar itu terus menghalangi seseorang untuk mengalami kemerdekaan. ${ }^{6}$ Masalah tersebut berbagai macam yang akhirnya menyerang mentalitas seseorang sehingga mengalami ketakutan. ${ }^{7}$ Apabila ketakutan itu tidak diselesaikan, maka akan mengarah kepada tindakan-tindakan yang negatif.

Dari kasus jemaat yang ditemukan, pada saat jemaat memiliki gambar diri yang rusak dan belum mengalami pemulihan, jemaat akan sulit untuk melayani Tuhan dengan baik dan benar. ${ }^{8}$ Karena jemaat tersebut akan merasa rendah diri, merasa tidak layak dan tidak akan bisa melakukan apapun dengan maksimal. Hal ini tentunya sejalan dengan mentalitas yang dimiliki selama ini. Hidup dalam ketakutan, diskriminasi ras dan sosial, dan ekonomi, gereja sebagai organisasi dan perpanjangan tangan Tuhan

${ }^{2}$ Apin Militia Christi, “Pengudusan Orang Percaya," in Pemikiran Teolog Gereja Bethel Indonesia Tentang Teologi Pentakosta (Jakarta: STT Bethel Indonesia, 2012), 151-171.

3 Demsy Jura and Wellem Sairwona, "Deskripsi Praktik Okultisme Di Kalangan Remaja Suku Dayak Maanyan Di Gereja Sidang-Sidang Jemaat Allah (GSJA) Wilayah Kabupaten Barito Timur Kalimantan Tengah," Jurnal Shanan 2, no. 2 (2018): 1-35.

${ }^{4}$ Esther Yudika Arijaya, "Hubungan Pemaafan (Forgiveness) Dengan Trauma Psikologis Pada Mereka Yang Pernah Mengalami Dan Tidak Mengalami Konflik Di Singkawang, Kalimantan Barat" (Universitas Kristes Satya Wacana, 2017).

${ }^{5}$ Frans Pantan et al., "Resiliensi Spiritual Menghadapi Disruption Religious Value Di Masa Pandemi Covid-19 Pada Lembaga Keagamaan," KURIOS: Jurnal Teologi dan Pendidikan Agama Kristen 7, no. 2 (2021).

${ }^{6}$ Barbara MacDonald and Cynthia Rich, Look Me in The Eye: The Me I See (Kansas: Beacon Hill Press of Kansas City, 2001).

7 Gernaida K R Pakpahan, "Analysis of Worring among Lecturers of Indonesian Bethel Theology on Covid-19," Medico-Legal Update 20, no. 4 (2020): 1330-1337; Gernaida Pakpahan, "Kecemasan Mahasiswa STT Bethel Indonesia Terhadap Covid-19," Jurnal Pendidikan Agama Kristen 3, no. 1 (2020): 20-33.

8 Hengki Wijaya, "Pengenalan Manusia Baru Di Dalam Kristus: Natur, Proses, Dan Fakta Serta Implikasi Teologis Dan Praktisnya," Jurnal Jaffray 14, no. 1 (2016): 109-130. 
membuat suatu program untuk memulihkan gambar diri dari setiap jemaat yang mengalami kerusakan, yaitu lewat program Renewal Life.

Istilah Renewal Life sendiri berasal dari dua kata yaitu "Renewal" yang diambil dari kata bahasa Inggris diartikan sebagai "pembaharuan." "Life" yang berarti "kehidupan" sehingga Renewal Life diartikan sebagai perubahan hidup dalam diri seseorang. Pada saat seseorang mengalami perjumpaan pribadi dengan Tuhan, maka pada saat itulah hidup orang itu mengalami sebuah pembaharuan hidup. Dibaharui dari hidup yang salah, dibaharui dari setiap luka yang membuat seseorang tidak mempunyai kekuatan lagi untuk menghidupi hidup ini. Seperti yang tertulis dalam Roma 12:2 agar manusia tidak mengubah diri menjadi seperti dunia, tetapi mengijinkan Allah mengubah bagian dalam dirinya dengan berpikir yang baru, yang menyenangkan Tuhan dan yang sempurna. Tujuan ini tentunya terkait erat dengan orang percaya yang menghidupi hidup dan cara hidup berbeda dengan orang yang belum mengenal Tuhan.

Program pelayanan Renewal Life ini ada terbagi atas 4 (empat) bagian: Pemulihan Gambar Diri, Pemulihan Kesembuhan Luka Batin, Pemulihan Hati Bapa dan Pelayanan Pelepasan serta formulir-formulir yang dibutuhkan. ${ }^{9}$ Program pelayanan ini dilaksanakan sebanyak empat kali dalam satu tahun. Dengan demikian, jemaat akan lebih menghidupi setiap kebenaran firman Tuhan dan lebih maksimal dalam melakukan pelayanan. Bagaimana kehidupan kerohanian jemaat GBI El Shaddai setelah mengikuti program "Renewal Life" di GBI El Shaddai, Pontianak? Bagaimana mengatasi kekurangan dalam program "Renewal Life" di GBI El Shaddai? Bagaimana dampak program "Renewal Life" terhadap kedewasaan rohani Jemaat di GBI El Shaddai Pontianak?

Penelitian terkait mengenai strategi kedewasaan jemaat pernah dilakukan oleh Marbun yang menyotori bahwa indikator jemaat bertumbuh adalah adanya perubahan hidup yang terlihat. Itulah sebabnya, Marbun menawarkan program Doulos Camp, Saya Pengikut Yesus (SPY), dan pelatihan lainnya untuk dilakukan. ${ }^{10}$ Sedangkan Gulo menyoroti peran gembala yang menjadi sentral dari pertumbuhan jemaat. ${ }^{11}$ Lain halnya dengan Mika dan Tuhumury meneliti bagaimana supaya pemuda mengalami pertumbuhan iman, yaitu dengan melakukan perkunjungan secara teratur, mengadakan ret-reat dan pendalaman Alkitab secara teratur. ${ }^{12}$ Sedangkan dalam kajian ini, peneliti memfokuskan studi evaluasi terhadap program Renewal Life yang telah lama berjalan di GBI El Shaddai untuk mendapatkan kelemahan dan kekuatannya.

\footnotetext{
9 Apin Militia Christi, “Jesus As the Healer," in Pemikiran Teolog Gereja Bethel Indonesia Tentang Teologi Pentakosta (Jakarta: STT Bethel Indonesia, 2012), 249-267.

10 Purim Marbun, "Strategi Dan Model Pembinaan Rohani Untuk Pendewasaan Iman Jemaat," Jurnal Ilmiah Religiosity Entity Humanity (JIREH) 2, no. 2 (2020): 151-169.

11 Hisikia Gulo, "Strategi Pelayanan Gembala Sidang Dalam Pembinaan Warga Gereja Bagi Kedewasaan Rohani Jemaat,” Eclesis Deo 5, no. 1 (2021): 17-28.

12 Mika and Pertonella Tuhumury, "Implementasi Strategi Pembinaan Menuju Pertumbuhan Rohani Pemuda GKII Jemaat Siduung Muara Berau," Jurnal Jaffray 11, no. 2 (2013): 191-208.
} 


\section{JURNAL LUXNOS}

Volume 7 Nomor 2, Desember 2021

\section{Metode Penelitian}

Penelitian ini menggunakan metode kualitatif deskriptif. Peneliti memaparkan fenomena secara khusus dalam satu tempat yang nantinya dapat diterapkan secara umum. ${ }^{13}$ Jenis data yang akan diperoleh lebih bersifat kualitatif, meliputi: pemahaman dan makna mengenai peran pembina dalam melakukan pelayanan pastoral, prinsip atau nilai-nilai ajaran yang digunakan, strategi penanganannya serta hambatan-hambatan yang dihadapi di GBI El Shaddai. Setelah mendapatkan data-data di lapangan, peneliti mengkonfirmasikan dengan melihat kajian teori terdahulu untuk melihat kesinambungan atau perbedaannya. ${ }^{14}$

Penelitian ini dilaksanakan di GBI El Shaddai. Pemilihan lokasi ini karena beberapa pertimbangan, yaitu: (1) Peneliti sendiri sebagai salah satu pengerja dan fulltime di GBI El Shaddai. Memang penilaian masih bersifat general dan terkesan subyektif, untuk itu peneliti melibatkan tim dalam melakukan observasi bersama supaya memperoleh data informasi lebih akurat dan memiliki nilai objektivitas tinggi; (2) Peneliti mempertimbangkan waktu, biaya dan tenaga karena lokasi tersebut terjangkau oleh peneliti; (3) Penelitian ini dapat menjadi kontribusi yang berarti tentunya bagi jemaat gereja, lembaga pendidikan, yayasan yang sejenis dan tempat di mana peneliti melayani. Subjek penelitian adalah orang, tempat atau benda yang diamati atau yang hendak diteliti. Untuk itu subjek penelitian dalam penelitian ini adalah para pembina (fasilitator) dan jemaat yang telah dipulihkan dan gembala jemaat di GBI El Shaddai. Sedangkan objek penelitian adalah bagaimana model pelayanan pastoral yang dilakukan oleh para pembina (fasilitator) terhadap jemaat yang mengalami keterikatan di GBI El Shaddai.

Informan penelitian adalah orang yang dimanfaatkan untuk memberikan informasi tentang situasi dan kondisi latar belakang penelitian. ${ }^{15}$ Informan merupakan orang yang benar-benar mengetahui permasalahan yang akan diteliti. ${ }^{16}$ Dalam penelitian ini terdapat informan kunci, yaitu orang-orang yang sangat memahami permasalahan yang hendak diteliti. Adapun yang dimaksud sebagai informan kunci dalam penelitian ini adalah ketua Renewal Life di GBI El Shaddai, 1 pembina yang mendampingi dan 3 jemaat yang dipilih secara random namun mampu berkomunikasi dengan baik.

\section{Hasil dan Pembahasan}

\footnotetext{
${ }^{13}$ H Schwartz and J Jacobs, Qualitative Sociology: A Method to The Madness (New York: Free Press, 1979).

14 Donny Charles Chandra, "FUnGSI TEORI DALAM METODE PENELITIAN KUALITATIF" (Reseach Gate, 2019).

15 Moleong, Metodologi Penelitian Kualitatif(Bandung: Remaja Rosdakarya, 2010).

16 Sugiyono, Metode Penelitian Administrasi (Bandung: Rosdikarya, 2016).
} 
Secara umum seluruh narasumber memahami apa, proses, tujuan, dan manfaat dari program Renewal Life. Memang ada perbedaan pemilihan kata sesuai dengan kebebasan setiap pribadi yang diwawancarai, namun demikian dapat disimpulkan bahwa setiap para narasumber memahami tentang program Renewal Life sebagai suatu wadah untuk memperlengkapi seluruh jemaat Kristus maju bergerak sesuai dengan kepenuhan Kristus dan memenuhi panggilan mereka. Perbedaan diksi ini tentunya terkait dengan usia dari narasumber. Narasumber yang usianya telah tua, sulit untuk mengucapkan frasa Renewal Life. Lain halnya dengan pemuda-pemuda yang secara kuat memahami istilah Renewal Life dan wacana dibalik frasa ini.

Di dalam penelitian ini, ditemukan ada tiga hal yang menjadi suatu daya tarik yang begitu menarik yang menjadi perhatian peneliti, yaitu faktor-faktor yang menentukan keberhasilan program "Renewal Life", cara mengatasi kekurangan dalam program "Renewal Life" bagaimana dampak program "Renewal Life" terhadap kedewasaan rohani jemaat di GBI El Shaddai Pontianak.

\section{Bagaimana Kehidupan Kerohanian Jemaat GBI El Shaddai Setelah Mengikuti Program "Renewal Life"}

Ada berbagai hal yang dirasakan oleh jemaat setelah mengikuti program "Renewal Life", secara khusus dalam kehidupan kerohanian jemaat tersebut. Kehidupan rohani memang menjadi fokus dalam program ini. Meskipun, dalam pembahasannya juga mengarah kepada kehidupan sosial dan ekonomi sebagai dampak yang mengikutinya. Secara spiritual atau rohani, mereka yang dahulu hidup dalam kegelapan, setelah mengikuti program Renewal Life kehidupannya mengalami perubahan hidup dalam terang Kristus sesuai dengan kebenaran firman Tuhan yang disampaikan. Tidak sulit untuk bersepakat dengan prinsip-prinsip kebenaran firman Tuhan, baik yang tersurat maupun tersirat. Mereka dulunya sulit untuk mengampuni setiap orang yang bersalah atau yang menyakiti hati, saat mengikuti program Renewal Life, lebih mudah mengambil keputusan untuk melepaskan pengampunan pada setiap orang yang menyakiti hati ataupun yang bersalah. Bahkan bukan hanya itu saja setiap peserta yang mengikuti program Renewal Life yang dulunya mereka sulit untuk mengelolah masalahnya setelah mengikuti program Renewal Life lebih mudah dapat menyelesaikan masalahnya sendiri. Beberapa perubahan lainnya:

a. Hampir semua jemaat mengalami perubahan setelah mengikuti program Renewal Life. Peserta memiliki kedewasaan dalam emosi ketika menghadapi masalah. Dahulu, rokok, alkohol dan judi adalah cara untuk menenangkan diri dari masalah, namun setelah mengikuti program Renewal Life, jemaat sudah memahami apa yang harus dilakukan ketika masalah datang tanpa melakukan tindakan yang salah.

b. Jemaat setelah mengikuti program Renewal Life memiliki pola pikir, cara pandang 
yang berbeda, baik terhadap dirinya sendiri maupun terhadap orang lain. Sehingga mudah mengalami pertumbuhan dalam kedewasaan rohani. Pemahaman akan dirinya yang rusak, kotor, anak tidak diingini karena hasil hubungan terlarang, dan merasa bodoh, sudah mulai memahami diri sendiri dan menerima keberadaan mereka.

c. Jemaat setelah mengikuti program Renewal Life memiliki kesadaran sendiri untuk mau terlibat, mengambil bagian dalam pelayanan di gereja tanpa harus didorong, dipaksa oleh pemimpin rohani untuk melayani. Selama ini untuk datang ibadah adalah perjuangan besar yang dilakukan oleh gereja. Namun, setelah mengikuti program Renewal Life ini, peserta bukan hanya rajin dan rutin untuk mengikuti kegiatan-kegiatan ibadah gereja. Tetapi, melayani dalam bidang-bidang yang disiapkan gereja.

d. Jemaat yang sudah mengikuti program Renewal Life memiliki kesadaran untuk mau bertumbuh dalam kedewasaan kerohaniaannya sehingga mau bergabung dalam suatu wadah komunitas pemuridan. Lebih lagi mengalami pertumbuhan dan kedewasaan kerohanian. Peserta mulai mengikis cara hidup dan filsafat hidup dari komunitas masyarakat sebelumnya, untuk mengikuti komunitas gereja. Tentunya mereka tidak secara drastis meninggalkan tempat tinggal dan sosial masyarakat di mana mereka hidup. Tetap berdampingan, tetapi tidak lagi menganut cara kehidupannya.

\section{Bagaimana Mengatasi Kekurangan Dalam Program "Renewal Life"}

Pelaksanaan program Renewal Life ada dijumpai kekurangan-kekurangan, seperti halnya ruangan tempat untuk melaksanakan program Renewal Life. Panitia pelaksana harus lebih persiapan dalam menyediakan ruangan yang lebih memadai (sesuai dengan kapasitas peserta) atau menyediakan pendingin ruangan lebih banyak (disesuaikan dengan kapasitas peserta). Itu berarti harus benar-benar memiliki persiapan yang cukup baik. Panitia pelaksana harus menyesuaikan dan memperhatikan antara jumlah peserta dan kondisi ruangan yang akan digunakan. Bila tidak menemukan tempat yang tepat, sebaiknya pesertanya dibatasi, agar perseta tersebut lebih maksimal untuk dilayani dan mengalami pemulihan.

Pada awal terbentuknya program ini, ruangan tidak menjadi masalah yang berarti. Tentunya karena partisipasi peserta yang masih sedikit. Namun, seiring berjalannya waktu, ruangan menjadi masalah. Panitia atau fasilitator menyiasatinya dengan memperbanyak pertemuan-pertemuan supaya seluruh peserta dapat terlayani dengan baik. Namun, dimasa pandemi ini, terlihat lebih baik dan mudah dikontrol karena kelas dapat dilakukan dengan menggunakan media online zoom meeting atau google meet. 


\section{Dampak program “Renewal Life” terhadap kedewasaan rohani jemaat}

Perbedaan bagian ini dengan bagian pertama, yaitu perubahan yang dialami oleh peserta dari mengikuti Renewal Life adalah kajian akan kedewasaan rohani. Kedewasaan rohani berkaitan dengan tindakan eksternal yang secara kasat mata dapat dilihat dan diukur. Bagi peserta yang mengikuti program Renewal Life mereka banyak mengalami pemulihan dalam pemulihan hati Bapa. Ini menjadi masalah paling banyak yang dialami peserta karena konteks daerah Kalimantan Barat yang kurang harmonis dalam keluarga. Dulunya mereka memiliki hubungan yang kurang baik dengan orang tua secara khusus bapak mereka. Kebencian ini berangkat dari orang tua yang memiliki sikap dan karakter yang dingin, cuek, orang tua yang pemarah, orang tua yang kurang perhatian terhadap anak. Dalam konteks masyarakat Kalimantan Barat, hubungan orang tua yang rusak tersebut mengakibatkan rusaknya hubungan dengan Tuhan. Tentu wajar, sebab tidak ada pribadi yang mengajarkan kepada mereka mengenai siapakah Yesus dalam keluarga. Sehingga setiap peserta yang mengalami kasus seperti ini memiliki pandangan yang salah tentang Bapa di Sorga. Karena hubungan dengan orang tua di bumi akan mempengaruhi bagaimana hubungannya dengan Bapa di Sorga. Setiap peserta mengalami pemulihan hubungan dengan orang tuanya, secara khusus bapak mereka yang akhirnya berdampak pada terbangunnya hubungan yang baik dengan Tuhan. Mereka memiliki sudut pandang yang benar dengan Bapa di sorga, bahkan kehidupan mereka terhadap orang tua juga mengalami pemulihan, seperti yang dirasakan oleh beberapa peserta.

Bagi peserta yang mengikuti program Renewal Life mereka banyak mengalami pemulihan dalam gambar diri mereka. Dulunya mereka memiliki pandangan yang salah, mereka berpikir karena keberdosaan dan hidup dalam dosa, menghilangkan kesegambaran dengan Allah. Padahal sesungguhnya tidak, karena kesegambaran dengan Allah menceritakan tentang karakter Allah pada peserta. Perubahan karakter terlihat dari keinginan untuk saling membantu, sabar, penguasaan diri, dan setia dalam segala bidang.

Melalui pelayanan program Renewal Life ini, seseorang belajar bahwa untuk bertumbuh secara rohani seseorang harus melepaskan diri dari masa lalu yang gelap, dari luka-luka yang sulit untuk diampuni. Hati harus bersih dan terbebas dari rasa bersalah untuk dapat menerima kebenaran firman Tuhan dengan utuh. Saat hati seseorang mengalami pemulihan maka orang itu dengan mudah untuk menerima kebenaran firman Tuhan. Setiap jemaat akan memiliki respon yang benar, mau melakukan firman Tuhan. Dengan itu, mereka mengalami lawatan Tuhan dan pertumbuhan kedewasaan kerohanian. ${ }^{17}$ Dampak dari sesi keempat dari sesi pelepasan,

17 Rick C. Howard, Kedewasaan Kristen (Jakarta: Lembaga Kursus Tertulis Internasional Indonesia, 2011). 
menurut hasil hasil penelitian yang diamati peneliti terhadap peserta yang mengikuti Renewal Life adalah terjadinya perubahan karakter. Untuk mengubah karakter mereka adalah tidaklah mudah, dibutuhkan kesadaran dari diri setiap peserta. ${ }^{18}$ Karakter merupakan suatu hal atau kebiasan yang sudah terbentuk lama dalam diri seseorang.

\section{Pembahasan Hasil Penelitian}

Temuan lapangan mengenai seperti apa pelaksanaan dan dampak program Renewal Life bagi jemaat di GBI El Shaddai adalah berupa pelayanan pembinaan rohani jemaat yang berdampak pada perubahan gambar diri jemaat, perubahan orientasi hidup dan perubahan karakter. Pelayanan pembinaan rohani jemaat yang dilakukan lewat program Renewal Life dilandaskan pada firman Tuhan dan berpusat pada Yesus Kristus. Sejalan dengan temuan penelitian mengenai pembinaan rohani jemaat terhadap program Renewal Life dengan pembinaan jemaat adalah proses seorang jemaat yang dilayani di gereja akan mengalami berbagai perubahan karakteristik dalam hal:
a. Pengenalan akan firman Tuhan.
b. Proses yang berlangsung bagi jemaat pada waktu mereka dibina, dididik, dan dibentuk dari kehidupan yang salah kepada kehidupan yang benar.
c. Proses menjadikan jemaat hidup dengan bijaksana dalam keselamatan yang mereka pegang di hadapan Tuhan.
d. Proses memperlengkapi jemaat Tuhan sehingga mereka dapat menjadi pelaku- pelaku perubahan yang baik. ${ }^{19}$

Dari hasil penelitian terungkap saat seorang jemaat belum mengalami perubahan seperti pemulihan dalam gambar diri, perubahan orientasi hidup dan perubahan karakter maka jemaat mengalami kematian secara rohani, sehingga membutuhkan kelahiran kembali atau kelahiran baru secara rohani. ${ }^{20}$ Akibat dari dosa yang belum diselesaikan, belum diakui ataupun dosa yang belum dibereskan pada Tuhan hubungan manusia dengan Tuhan menjadi renggang dan tentunya memiliki cara pandang yang salah tentang Tuhan. Seperti halnya saat dosa pertama kali masuk ke dalam dunia melalui ketidaktaatan Adam dan Hawa yang mengakibatkan gambar dan rupa Yesus dalam diri manusia dicemari, sehingga dosa menjalar kepada setiap manusia (Rm. 3:10-12, 23; 5:12) dan sejak itu dosa di turunkan kepada semua manusia (Rm. 5:12; 1 Kor. 15:22). Fakta ini tidak dapat disangkal. Seharusnya ini menjadi pemahaman

18 Desy Masrina, Muryati, and Suwondo Sumen, "Dampak Pemuridan Bagi Kaderisasi Pelayan Tuhan Dan Pertumbuhan Gereja Bethel Indonesia Toho," Jurnal Gamaliel: Teologi Praktika 3, no. 2 (2021): 127-140.

19 Purim Marbun, Pembinaan Jemaat (Yogyakarta: ANDI Offised, 2015), 25.

20 Jarot Wijanarko, Pemulihan Gambar Diri (Jakarta: Suara Pemulihan, 2012). 
setiap manusia yang beragama yang mengakibatkan kepada tindakan diri mencari jalan keluar dari masalah ini. ${ }^{21}$

Akibat dari dosa tersebut terjadi kerusakan secara keseluruhan dalam perbuatan, sehingga manusia cenderung tidak memilki hati nurani yang baik, dan tidak memiliki dorongan untuk membangun hubungan dengan Tuhan. Manusia lebih menuruti setiap bentuk perbuatan dosa, bahkan saat seseorang jatuh dalam dosa, tidak lagi mampu melakukan hal-hal yang baik dalam pandangan manusia ataupun dalam pandangan Allah. Kerusakan yang diakibatkan perbuatan dosa menjangkau setiap aspek natur dan kemampuan manusia seperti pikiran, hati nurani, kehendak, emosi, dan keberadaan manusia secara menyeluruh sehingga membuat dalam diri manusia ketidak layakan saat menghampiri-Nya.

Saat seseorang belum lahir baru dan belum mengalami pemulihan maka orang tersebut tidak mampu melakukan dan memikirkan apa yang dikehendaki oleh Allah terhadap dirinya. Tanpa campur tangan Roh Kudus seorang yang belum lahir baru tidak mungkin mampu mengubah arah hidupnya, walaupun masih mampu melakukan bentuk-bentuk kebaikan dan kebajikan tertentu. Akan tetapi kebaikan yang dilakukan tidak didorong oleh karena kasih kepada Kristus. Keberdosaan manusia membuat manusia tidak mampu melakukan dan merespon hal-hal rohani dari Allah (Rm 3:920).22 Dapat dilihat manusia membutuhkan suatu tindakan perubahan yang radikal dan menyeluruh dalam kehidupannya yang pada akhirnya mampu untuk dapat kembali melakukan apa yang benar, yang baik, yang dikehendaki Allah atau menurut pandangan Tuhan. Lewat program pelayanan pembinaan rohani yaitu Renewal Life membantu setiap jemaat mengalami perubahan, pemulihan dalam hidupnya. Sehingga jemaat mengalami pertumbuhan kedewasan rohaninya. ${ }^{23}$

Dalam melaksanakan pembinaan rohani lewat program Renewal Life, Tuhan telah memperlengkapi para pemimpin atau pelayan Tuhan dengan sejumlah karunia. Peneliti memahami dan percaya bahwa karunia Roh Kudus masih bekerja hingga saat ini yang bertujuan untuk membangun gereja.24 Tujuannya agar dalam melakukan pembinaan, para hamba Tuhan atau pelayan Tuhan dengan baik menuntun jemaatnya

21 Federans Randa, "Karya Keselamatan Allah Dalam Yesus Kristus Sebagai Jaminan Manusia Bebas Dari Hukuman Kekal Allah," LOGON ZOES: Jurnal Teologi, Sosial dan Budaya 3, no. 1 (2020): 35-62.

22 Rubin Adi Abraham, Makin Tertekan Makin Berkemenangan (Yogyakarta: ANDI Offised, 2017).

23 Magdalena Tomatala, Konselor Kompeten; Pengantar Konseling Terapi Untuk Pemulihan (Jakarta: YT Leadership Foundation IFTK Jaffray, 2000).

24 Gede Widiada, “Gembala Sidang Yang Visioner," in Reaffirming Our Identity: Isu-Isu Terpilih Menjawab Perubahan Sekaligus Mempertahankan Identitas, ed. Junifrius Gultom and Frans Pantan (Jakarta: Bethel Press, 2014), 335-348; Frans Pantan, "Kompilasi Bahan Ajar Christian Leadership" (Jakarta: STT Bethel Indonesia, 2007). 
dalam membimbing dan mengarahkannya sesuai dengan firman Tuhan. ${ }^{25}$ Sehingga pembinaan yang dilakukan bukan hanya kemampuan untuk mengajar dan mendidik, membina, tetapi juga hikmat dari Roh Kudus memampukan setiap pelayan Tuhan dalam program Renewal Life untuk membina dan bersama-sama bertumbuh dalam pengenalan akan Tuhan dan dalam kedewasaan. Tentunya, para fasilitator juga memperlengkapi diri dengan belajar dasar-dasar firman Tuhan, dan yang terutama adalah konseling pastoral guna menjalankan program dengan baik. ${ }^{26}$

Pelaksanaan pembinaan yang dilakukan sehingga berdampak pada perubahan hidup pada jemaat yang mengikut program Renewal Life berupa konseling. Konseling yang dilakukan dapat mempengaruhi perubahan perilaku dari sebagian dari kepribadian jemaat yang di konseling. ${ }^{27}$ Saat peserta dikonseling tujuannya untuk menciptakan kondisi yang nyaman sehingga terjadi perubahan dalam diri jemaat yang dikonseling. Saat jemaat dikonseling maka harus segera ditindaklanjuti, apabila tidak maka perubahan yang terjadi tidak sesuai dengan seperti yang diharapkan. Pembinaan yang dilakukan diharapkan jemaat memiliki pola pikir yang baru dan baik tentang dirinya, dan juga mampu melihat dengan sudut pandang yang benar dalam menghadapi masalah. Pembinaan yang dilakukan disertai dengan pendampingan, yaitu lewat fasilitator atau mentor. Tujuan diadakannya pendampingan akan membantu jemaat atau peserta yang mengikuti program Renewal Life pada akhirnya akan mampu menolong dirinya sendiri, baik pada saat ini, maupun nantinya ketika menghadapi persoalan lagi. ${ }^{28}$

Seperti apa yang disampaikan Wiryasaputra dan Handayani, tujuan pendampingan antara lain: ${ }^{29}$

a) Berubah menuju Pertumbuhan: dengan tujuan jemaat mengalami perubahan dan dengan demikian jemaa tersebut dapat mendampingi orang lain lagi yang mengalami persoalan.

b) Mencapai pemahaman diri secara penuh dan utuh, jemaat dibantu memahami potensi diri, peluang-peluangnya, sehingga ketika menghadapi persoalan tidak mudah menyerah.

c) Mampu berkomunikasi dengan lebih baik

25 Johni Hardori, "The Lost of Pastoral Ministry," in Reaffirming Our Identity: Isu-Isu Terpilih Menjawab Perubahan Sekaligus Mempertahankan Identitas, ed. Junifrius Gultom and Frans Pantan (Jakarta: Bethel Press, 2014), 285-304.

26 Fibry Jati Nugroho, "Pendampingan Pastoral Holistik: Sebuah Usulan Konseptual Pembinaan Warga Gereja," Evangelikal: Jurnal Teologi Injili dan Pembinaan Warga Jemaat 1, no. 2 (2017): 139.

27 Asih Rachmani E Sumiwi and Reniyana Reniyana, "MANFAAT KONSELING BAGI PERUBAHAN KARAKTER PESERTA RETREAT ENCOUNTER GBI KELUARGA ALLAH SURAKARTA PERIODE JANUARIMARET 2017," REGULA FIDEI: Jurnal Pendidikan Agama Kristen 3, no. 2 (2018): 122-136.

28 Gary R Collins, Konseling Kristen Yang Efektif (Malang: Literatur SAAT, 2017).

29 Wiryasaputra and Handayani, Pengantar Konseling Pastoral (Malang: AKPI-IAPC, 2013), 21-22. 
d) Mempraktekan dan melakukan tingkah laku baru yang lebih sehat, pendampingan akan mengarahkan jemaat memahami perilaku yang benar dan pantas sesuai dengan etika dan moral pada umumnya. Wiryohadi dkk menambahkan bahwa pendampingan yang dilakukan secara intensif akan melahirkan kebiasaan baru dari jemaat yang positif. ${ }^{30}$

e) Belajar mengekspresikan diri secara penuh dan utuh, membutuhkan keberanian dan kepercayaan pada diri sendiri.

f) Mampu bertahan, pendampingan membantu konseli untuk mampu bertahan di masa sukar.

g) Menghilangkan gejala disfungsional, pendampingan diharapkan dapat meminimalisir kemungkinannya secara dini.

Dari bentuk-bentuk pelayanan yang digunakan pada program Renewal Life sangat signifikan dalam membantu perubahan hidup jemaat yang mengalami keterikatan dan mau dilayani. Poin utamanya adalah keinginan jemaat untuk keluar dari keadaan mereka selama ini. ${ }^{31}$ Itu sebabnya, para fasilitator mesti mulai dengan penyadaran dari peserta bahwa mereka sedang dalam keadaan tidak baik dan mesti keluar dari keadaan itu. Sederhananya bahwa apa yang dilakukan selama ini adalah salah. ${ }^{32}$

Dalam hasil penelitian baik validasi data dan narasumber di lapangan, maka peneliti membuat kebijakan-kebijakan terkini yaitu tentang kedewasaan rohani jemaat di GBI El Shaddai lewat program Renewal Life, yaitu: Adanya keterbukaan hati setiap peserta untuk mau dipulihkan, adanya campur tangan kuasa Roh Kudus dalam menjamah setiap hati peserta, adanya peran penting dari seorang pemimpin (gembala) dalam menyukseskan sebuah program gereja, kelompok sel ataupun wadah pemuridan, yang harus terus dipertahankan dan dikembangkan. Sedangkan faktor-faktor lainnya seperti, penatalayanan, keteladanan pemimpin, kesatuan tim penyelenggara, doa, dan akomodasi akan terus ditingkatkan sehingga tidak hanya satu faktor yang menonjol, sehingga memiliki pengaruh yang besar bagi suksesnya pelayanan program Renewal Life.

Seluruh tim penyelenggara program Renewal Life dan gembala membuat strategi yang relevan dan kekinian bagi kedewasaan rohani jemaat lewat program Renewal Life

30 Wiryohadi Wiryohadi, Periskila Sitompul, and Gede Widiada, "Model Pendampingan Pastoral Bagi Remaja Yang Mengalami Broken Home Guna Membangun Citra Dan Konsep Diri Yang Benar," Diegesis: Jurnal Teologi 6, no. 2 (2021): 55-71.

31 Purim Marbun et al., "Gereja, Ibadah, Dan Iman: Sebuah Studi Deskriptif Strategi Penggembalaan GBI Sentral Tomang Dalam Menumbuhkan Motivasi Beribadah Jemaat," Matheo: Jurnal Teologi/Kependetaan 9, no. 1 (2019): 13-24.

32 Widodo Gunawan, “Pastoral Konseling: Deskripsi Umum Dan Praktik,” Jurnal Abdiel: Khazanah Pemikiran Teologi, Pendidikan Agama Kristen, dan Musik Gereja 2, no. 1 (2018): 96. 
dikemudian hari. Pelayanan program Renewal Life akan mengalami dampak yang besar terhadap kedewasaan rohani jemaat melalui:

a. Terbentuknya tim yang solid yang memiliki hati yang penuh dengan belas kasih terhadap pertumbuhan kedewasaan jemaat. Ini menjadi faktor penting mengingat semakin berjalannya waktu dan dampak yang dihasilkan, maka semakin banyak peserta yang ingin dilayani secara khusus dalam program ini. Jika tim tidak memiliki keinginan untuk membantu mereka dan bosan karena banyaknya masalah yang perlu dihadapi dari para peserta, maka proses Renewal Life tidak akan berjalan dengan baik.

b. Memiliki tim pelayanan yang relevan bagi generasi selanjutnya. Program ini telah menyasar kepada seluruh usia. Itu sebabnya, tim pun perlu dari segala usia supaya ketika proses konseling, peserta dengan berani terbuka dan berbicara layaknya seorang sahabat.

c. Membangun tim SDM yang lebih banyak. SDM diambil dari peserta yang sudah mengikuti program ini. Tentunya tidak secara langsung, melainkan ada pelatihan khusus kepada mereka untuk dapat menjadi fasilitator.

d. Seorang pemimpin (gembala) harus menganggarkan dana untuk mendukung keberhasilan program Renewal Life demi tercapainya kedewasaan rohani dalam jemaat. Dalam rapat anggaran gereja, pendanaan banyak berfokus kepada penginjilan dan program event. Melihat keberhasilan dari program ini, maka gereja semestinya memberikan anggaran khusus untuk berjalannya program ini.

Menanggapi masalah diatas, maka penulis memberikan beberapa upaya yang dapat dilakukan oleh para pembaca di gereja lokal masing-masing sebagai berikut:

\section{Strategi 1:}

a. Menyiapkan tim SDM yang solid dan materi-materi program Renewal Life lebih efektif lagi. Materi disusun dengan para leaders yang menggembalakan ditingkatannya masing-masing, lalu disusun berdasarkan kategori. Tema yang sama mesti dilakukan pendekatan dengan diksi dan cara yang berbeda.

b. Memberikan informasi yang jelas dan mensosialisasikan kepada jemaat. Jika menunggu hasil dari program, maka membutuhkan waktu lama untuk merealisasinya. Oleh karenanya, diumumkan kepada jemaat menjadi jawaban. Selain itu, kesaksian-kesaksian mereka yang telah mengikuti program ini menjadi penting untuk disampaikan. Hal ini menjadi dorongan tersendiri untuk jemaat yang masih hidup dalam keterikatan seperti yang dideskripsikan di atas, untuk mau ikut. Terkadang ada anggapan dari jemaat bahwa mereka bisa dengan sendirinya keluar dari masalah itu semua. Hal ini karena mereka malu untuk mengungkapkan kesalahan yang dilakukan selama ini. Dengan adanya kesaksian yang disertai dorongan akan tujuan program ini, 
jemaat tidak akan malu untuk mengikutinya.

c. Menyiapkan ruangan, tempat, dan menyediakan biaya sesuai dengan kebutuhan (jumlah) peserta yang dibutuhkan.

\section{Strategi 2:}

a. Mengundang para narasumber/pembicara, fasilitator, yang berkualitas, yang memiliki hati yang penuh belas kasihan terhadap jiwa-jiwa yang hendak dilayani. Hal ini dilakukan apabila dalam proses kekurangan SDM. Atau juga ingin melakukan pembaharuan materi yang akan diajarkan kepada para peserta.

b. Membawa program Renewal Life sebagai sebuah agenda wajib yang harus didukung oleh anggaran dana dari gereja

\section{Kesimpulan}

Rekonsiliasi dengan pribadi terhadap kejadian-kejadian yang menyedihkan di masa lalu dan orang-orang yang terlibat di dalamnya, dan perubahan karakter yang mengikutinya. Hal ini memberikan sumbangsih wadah bagi jemaat yang menyadari bahwa dirinya sedang melakukan hal yang salah. Penulis memberikan saran, kepada Tim Pelaksana program Renewal Life adalah sebuah program yang baik untuk pelayanan pemulihan diri jemaat maupun di luar jemaat gereja yang mau dipulihkan. Menurut penulis ada baiknya program Renewal Life ini harus ditingkatkan lebih lagi, baik dalam mekanisme sistematika pelaksanaanya, tempat dan orang-orang yang terlibat dalam program Renewal Life. Pelatihan dengan para profesional dapat menjadi jawaban bagi para fasilitator supaya memperlengkapi tata bahasa dan cara konseling yang relevan, agar lebih berdampak dan program Renewal Life ini terus menjadi berkat bagi setiap jemaat yang membutuhkan, maka dibutuhkan kesiapan tim pelaksana baik secara rohani maupun jasmani. Setiap tim pelaksana Renewal Life selalu terkoneksi dengan Roh Kudus dan memiliki kehidupan rohani yang baik. Sebab konteks pelayanan yang dihadapi adalah orang-orang yang masih percaya dengan kuasa, filsafat, dan cara hidup nenek moyang atau agama-agama lama. Penulis mendorong gereja untuk melaksanakan Renewal Life sebab program yang berfokus pada pemulihan inner manusia berdampak besar bagi outer manusia.

\section{Referensi}

Abraham, Rubin Adi. Makin Tertekan Makin Berkemenangan. Yogyakarta: ANDI Offised, 2017.

Arijaya, Esther Yudika. “Hubungan Pemaafan (Forgiveness) Dengan Trauma Psikologis Pada Mereka Yang Pernah Mengalami Dan Tidak Mengalami Konflik Di Singkawang, Kalimantan Barat." Universitas Kristes Satya Wacana, 2017. 
Chandra, Donny Charles. "FUNGSI TEORI DALAM METODE PENELITIAN KUALITATIF." Reseach Gate, 2019.

Christi, Apin Militia. "Jesus As the Healer." In Pemikiran Teolog Gereja Bethel Indonesia Tentang Teologi Pentakosta, 249-267. Jakarta: STT Bethel Indonesia, 2012.

- _- "Pengudusan Orang Percaya." In Pemikiran Teolog Gereja Bethel Indonesia Tentang Teologi Pentakosta, 151-171. Jakarta: STT Bethel Indonesia, 2012.

Collins, Gary R. Konseling Kristen Yang Efektif. Malang: Literatur SAAT, 2017.

Gede Widiada. “Gembala Sidang Yang Visioner." In Reaffirming Our Identity: Isu-Isu Terpilih Menjawab Perubahan Sekaligus Mempertahankan Identitas, edited by Junifrius Gultom and Frans Pantan, 335-348. Jakarta: Bethel Press, 2014.

Gulo, Hisikia. "Strategi Pelayanan Gembala Sidang Dalam Pembinaan Warga Gereja Bagi Kedewasaan Rohani Jemaat.” Eclesis Deo 5, no. 1 (2021): 17-28.

Howard, Rick C. Kedewasaan Kristen. Jakarta: Lembaga Kursus Tertulis Internasional Indonesia, 2011.

Johni Hardori. "The Lost of Pastoral Ministry." In Reaffirming Our Identity: Isu-Isu Terpilih Menjawab Perubahan Sekaligus Mempertahankan Identitas, edited by Junifrius Gultom and Frans Pantan, 285-304. Jakarta: Bethel Press, 2014.

Jura, Demsy, and Wellem Sairwona. “Deskripsi Praktik Okultisme Di Kalangan Remaja Suku Dayak Maanyan Di Gereja Sidang-Sidang Jemaat Allah (GSJA) Wilayah Kabupaten Barito Timur Kalimantan Tengah." Jurnal Shanan 2, no. 2 (2018): 1-35.

MacDonald, Barbara, and Cynthia Rich. Look Me in The Eye: The Me I See. Kansas: Beacon Hill Press of Kansas City, 2001.

Marbun, Purim. "Strategi Dan Model Pembinaan Rohani Untuk Pendewasaan Iman Jemaat." Jurnal Ilmiah Religiosity Entity Humanity (JIREH) 2, no. 2 (2020): 151-169.

Marbun, Purim, Ivonne Sandra Sumual, Andrew Pieters Mandang, Ferdinand Edu, and Fransina Watimena. “Gereja, Ibadah, Dan Iman: Sebuah Studi Deskriptif Strategi Penggembalaan GBI Sentral Tomang Dalam Menumbuhkan Motivasi Beribadah Jemaat." Matheo: Jurnal Teologi/Kependetaan 9, no. 1 (2019): 13-24.

Masrina, Desy, Muryati, and Suwondo Sumen. "Dampak Pemuridan Bagi Kaderisasi Pelayan Tuhan Dan Pertumbuhan Gereja Bethel Indonesia Toho." Jurnal Gamaliel: Teologi Praktika 3, no. 2 (2021): 127-140.

Mika, and Pertonella Tuhumury. "Implementasi Strategi Pembinaan Menuju Pertumbuhan Rohani Pemuda GKII Jemaat Siduung Muara Berau." Jurnal Jaffray 11, no. 2 (2013): 191-208. 
Moleong. Metodologi Penelitian Kualitatif. Bandung: Remaja Rosdakarya, 2010.

Nugroho, Fibry Jati. "Pendampingan Pastoral Holistik: Sebuah Usulan Konseptual Pembinaan Warga Gereja." Evangelikal: Jurnal Teologi Injili dan Pembinaan Warga Jemaat 1, no. 2 (2017): 139.

Pakpahan, Gernaida. “Kecemasan Mahasiswa STT Bethel Indonesia Terhadap Covid-19.” Jurnal Pendidikan Agama Kristen 3, no. 1 (2020): 20-33.

Pakpahan, Gernaida K R. "Analysis of Worring among Lecturers of Indonesian Bethel Theology on Covid-19." Medico-Legal Update 20, no. 4 (2020): 1330-1337.

Pantan, Frans. "Kompilasi Bahan Ajar Christian Leadership." Jakarta: STT Bethel Indonesia, 2007.

Pantan, Frans, Priskila Issak Benyamin, Johni Handori, Yuel Sumarno, and Sadrakh Sugiono. "Resiliensi Spiritual Menghadapi Disruption Religious Value Di Masa Pandemi Covid-19 Pada Lembaga Keagamaan." KURIOS: Jurnal Teologi dan Pendidikan Agama Kristen 7, no. 2 (2021).

Purim Marbun. Pembinaan Jemaat. Yogyakarta: ANDI Offised, 2015.

Putra, Adi. "Hakikat Pertumbuhan Gereja Berdasarkan Kisah Para Rasul 2: 41-47." BIA': Jurnal Teologi dan Pendidikan Kristen Kontekstual 3 (2020): 262-281.

Randa, Federans. "Karya Keselamatan Allah Dalam Yesus Kristus Sebagai Jaminan Manusia Bebas Dari Hukuman Kekal Allah." LOGON ZOES: Jurnal Teologi, Sosial dan Budaya 3, no. 1 (2020): 35-62.

Schwartz, H, and J Jacobs. Qualitative Sociology: A Method to The Madness. New York: Free Press, 1979.

Sugiyono. Metode Penelitian Administrasi. Bandung: Rosdikarya, 2016.

Sumiwi, Asih Rachmani E, and Reniyana Reniyana. "MANFAAT KONSELING BAGI PERUBAHAN KARAKTER PESERTA RETREAT ENCOUNTER GBI KELUARGA ALLAH SURAKARTA PERIODE JANUARI-MARET 2017." REGULA FIDEI: Jurnal Pendidikan Agama Kristen 3, no. 2 (2018): 122-136.

Tomatala, Magdalena. Konselor Kompeten; Pengantar Konseling Terapi Untuk Pemulihan. Jakarta: YT Leadership Foundation IFTK Jaffray, 2000.

Widodo Gunawan. "Pastoral Konseling: Deskripsi Umum Dan Praktik." Jurnal Abdiel: Khazanah Pemikiran Teologi, Pendidikan Agama Kristen, dan Musik Gereja 2, no. 1 (2018): 96.

Wijanarko, Jarot. Pemulihan Gambar Diri. Jakarta: Suara Pemulihan, 2012.

Wijaya, Hengki. "Pengenalan Manusia Baru Di Dalam Kristus: Natur, Proses, Dan Fakta 


\section{JURNAL LUXNOS}

Volume 7 Nomor 2, Desember 2021

Serta Implikasi Teologis Dan Praktisnya." Jurnal Jaffray 14, no. 1 (2016): 109-130. Wiryasaputra, and Handayani. Pengantar Konseling Pastoral. Malang: AKPI-IAPC, 2013. Wiryohadi, Wiryohadi, Periskila Sitompul, and Gede Widiada. "Model Pendampingan Pastoral Bagi Remaja Yang Mengalami Broken Home Guna Membangun Citra Dan Konsep Diri Yang Benar.” Diegesis: Jurnal Teologi 6, no. 2 (2021): 55-71. 